\title{
La acedia como causa de la caída del nous en Orígenes y Evagrio Póntico
}

\author{
Rubén Peretó \\ UNIVERSIDAD NACIONAL DE CUYO \\ rpereto@gmail.com
}

Resumen: Henri Crouzel, en su ya clásico libro sobre Orígenes, menciona al pasar, cuando trata acerca de la caída de las almas, que el motivo podría deberse, según el Alejandrino, a la acedia entendida como disgusto por la contemplación (Origène, [P. Lethielleux, Paris, 1985], 273). Es esta la conclusión a la que se arriba luego de la lectura del pormenorizado análisis de Marguerite Harl acerca de la expresión kópov $\lambda \alpha \beta \varepsilon \tilde{i} v$ en el De principiis, F. L. Cross (ed.), Studia Patristica VIII, Texte und Untersuchungen 93 [Akademie Verlag, Berlin, 1966] 373-405). La propuesta de este trabajo es revalidar algunas de las observaciones de Harl en el trabajo mencionado y confrontarlas con la obra de Evagrio Póntico quien, en Kephalaia gnostica, replica lo afirmado por Orígenes. Pero, en este caso su afirmación adquiere una nueva dimensión debido a la profunda y completa teorización que posee Evagrio sobre la acedia.

Palabras clave: Evagrio Póntico, Orígenes, Acedia, Negligencia.

Abstract: Henri Crouzel, in his classical book on Origen, says that the fall of souls was caused by acedia as displease for the contemplation (Origène, [P. Lethielleux, Paris, 1985], 273). Marguerite Harl analyses deeply the expression кópov $\lambda \alpha \beta \varepsilon i ̃ v$ in the De principiis, in F. L. Cross (ed.), Studia Patristica VIII, Texte und Untersuchungen 93 [Akademie Verlag, Berlin, 1966] 373-405). This paper aims to ratify some of the Harl's assertions and compare them with Evagrius Ponticus' works who, in Kephalaia gnostica, repeats Origen's assertion. The deep and complete Evagrius' theorization on the sloth adds interesting nuances to the discussion.

Keywords: Evagrius Ponticus, Origen, Acedia, Sloth. 


\section{INTRODUCCIÓN}

Henri Crouzel, en su ya clásico libro sobre Orígenes, menciona al pasar, cuando trata acerca de la caída de las almas, que el motivo de esta podría deberse, según el Alejandrino, a la acedia entendida como disgusto por la contemplación ${ }^{1}$. Es esta la conclusión a la que se arriba luego de la lectura del pormenorizado análisis de Marguerite Harl acerca de la expresión кó@ov $\lambda \alpha \beta \varepsilon i ̃ v$ en el De principiis ${ }^{2}$. Sería entonces una situación de acedia la que provocó la caída de los noein de la Unidad original y su conversión en almas.

La propuesta de este trabajo es revalidar algunas de las observaciones de Harl en el trabajo mencionado y confrontarlas con la obra de Evagrio Póntico quien, en las Kephalaia gnostica, replica lo afirmado por Orígenes ${ }^{3}$. Pero, en este caso su afirmación adquiere una nueva dimensión debido a la profunda y completa teorización que posee Evagrio sobre la acedia.

Son las condenas antioriginistas del año 553 las que aportan la expresión Kó@ov $\lambda \alpha \beta \varepsilon i ̃ v \tau \tilde{\varsigma} \theta \varepsilon \omega \varrho i ́ a s$, la cual no aparece en la obra de Orígenes. El texto de la primera anatema afirma: "Si alguno dice que el conjunto de todos los seres racionales eran intelectos incorpóreos e inmateriales [...] y que, hartados de la contemplación divina, se volvieron hacia lo peor..." . La causa que aquí se aduce para explicar la caída es el hartazgo o la saciedad - kó@os- de la contemplación ${ }^{5}$. En Evagrio y en el De principiis, en cambio, la causa que se alega es la negligencia ${ }^{6}$. A continuación, analizaré el tema de la caída en la literatura patrística anterior a Orígenes, en la obra de este autor y, finalmente, en Evagrio Póntico, a fin de

Cf. H. Crouzel, Origène (P. Lethielleux, Paris 1985), 273.

2 Cf. M. HARL, «Recherches sur l'origénisme d'Origène; La «satiété» de la contemplation comme motif de la chute des âmes», F. L. Cross, Studia Patristica VIII, Texte Und Untersuchungen 93 (Akademie Verlag, Berlin 1966), 373-405.

3 Cf. Evagrio Póntico, Les six centuries des Képhalaia Gnostica d'Évagre le Pontique. A. Guilleaumont, ed. (Brepols, Turnhout 1958), I, 49; III, 28.

4 Mansi, SCC, IX, 396.

5 En esto punto podría ponerse la objeción que, si bien la expresión aparece en las condenas, no necesariamente debe asumirse que la misma pertenezca a Orígenes. Sin embargo, el artículo menciona de M. Harl despeja esa duda. Cf. especialmente, pp. 375-376.

6 Orígenes, Traités des príncipes II, 9, 2, H. Crouzel y M. SimonetTi, edd. (Sources Chrétiennes 252; Cerf, Paris 2008) 354, 43-45. 
concluir mostrando la complementariedad de los conceptos de hartazgo y negligencia, por una parte y, de este último, con el de acedia.

\section{LA CAÍDA EN LA LITERATURA ANTERIOR A ORÍGENES}

La idea de que las almas de los hombres han "caído" de un estado superior en el que han sido creadas y, como resultado de esa caída, habitan los cuerpos, encuentra uno de sus principales exponentes en Platón quien le da forma en su mito de las almas aladas ${ }^{7}$ Escribe: "Pero cuando (el alma), por no haber podido seguirlo (a lo divino), no lo ha visto, $y$ por cualquier azaroso suceso se va gravitando llena de olvido y dejadez, debido a este lastre, pierde las alas y cae a tierra" ${ }^{8}$. El análisis de este conocido texto permite identificar tres elementos: el alejamiento de lo divino provoca que el alma se torne pesada y se llene de olvido $(\lambda \eta \dot{\theta \eta})$ y

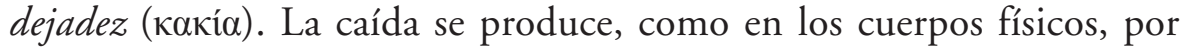
efecto de la gravedad: el alma se vuelve grávida o pesada y, entonces, naturalmente cae del estadio elevado de contemplación de lo divino ${ }^{9}$. El motivo por el cual se produce esta gravidez o situación de pesadumbre es el olvido y la dejadez. El volver la mirada de las realidades superiores para dirigirla al mundo inferior, provoca necesariamente no solo la distracción con respecto a la contemplación de Dios, sino también la desidia o relajamiento.

La expresión que utiliza el Fedro para explicar una de las dos causas de la caída es кakía. Varias versiones a lenguas contemporáneas han tra-

\footnotetext{
7 Cf. Platón, Fedro 245c-248c.
}

8 Fedro 248c. Traducción de C. García Gual - M. Martínez Hernández - E. LleDÓ Í́̃IGO (Gredos, Madrid 1982), 346.

9 Resulta por demás significativo que filósofos medievales como Alejandro de Hales (Alejandro de Hales, Summa Theologica II pars, II libri, inq. III, tract. IV, sect. II, quaest. I, tit. IV, cap. 1 - 559; ed. B. Marrani, t. III (Ex Typographia Collegii S. Bonaventurae, Ad Claras Aquas 1930) y Alberto Magno (Alberto Magno, II Summae Theologiae, tract. XVIII, q. 118, a.1, ad ultimum. ed. Borgnet (L. Vivès, Paris, 1895), t. 33, p. 370), califiquen a la acedia como tristia aggravans, es decir, tristeza que apesadumbra o vuelve pesada a la persona que la soporta. Toman este concepto de la traducción que hace Burgundio de Pisa del De fide orthodoxa de San Juan Damasceno (Juan Damasceno, De fide orthodoxa. Versions of Burgundio and Cerbanus, ed. E. M. Buytaert (Franciscan Institute Publications. Texte Series 8; The Franciscan Institute, New York 1955), c. 28, p. 121). Cf. R. Peretó Rivas, "La recepción del concepto de acedia en la obra de Alberto Magno", en Scripta Mediaevalia 6 (2013), 127-138. 
ducido esta expresión como maldad, vicio o incompetencia. Sin embargo, considero que es apropiado, en este caso, traducirla por desgano, apatía, desinterés o, incluso, acedia. Es este el modo en el cual traduce la versión española de García Gual, y en el mismo sentido lo hace la alemana de Schleiermacher que escribe Trägheit ${ }^{10}$. Por otra parte, E. des Place considera que la primera acepción de este término griego es lâcheté, es decir, dejadez o falta de energía moral para acometer el propio deber ${ }^{11}$.

Platón, por tanto, considera que es el estado de indolencia y desánimo el que, junto al olvido, tornan a las almas pesadas provocando que caigan de la unidad y de la contemplación de Dios. Dicho de otro modo, las almas se "aburren" de la contemplación de las realidades superiores y, por ese motivo, se precipitan hacia las inferiores. Y propongo en este caso la concepción etimológica del aburrimiento, es decir, ab horrere o rechazo u odio hacia algo.

No aparece en el caso del texto platónico la idea de saciedad. Sin embargo, esta podría ubicarse en los orígenes de la dejadez. Es decir, el nous comienza a experimentar la dejadez debido a un hartazgo o saciedad. Kógos, en este caso, podría adquirir incluso la connotación de insolencia puesto que, una vez saciado, al nous ya no le importa alejarse o ser negligente con respecto a la contemplación. Este es el sentido de la expresión кógos que aparece, por ejemplo, en las Odas Olímpicas de Píndaro por lo que sería una acepción posible ${ }^{12}$.

Filón de Alejandría utiliza con cierta frecuencia la expresión кó@os. Es la falta propia de quienes carecen del dominio de sí, ṽßpıৎ, y, también, el entumecimiento del intelecto que ocurre cuando los sentidos se han hartado de las cosas sensibles. Se trata de la torpeza que se apodera del hombre a raíz de la pereza de los sentidos, o de su negligencia. De este

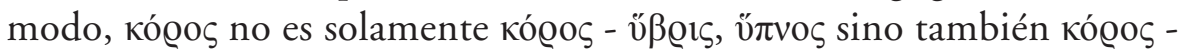
vँ $\pi$ os; no solo lo que excita sino también lo que adormila ${ }^{13}$.

10 Cf. Platón, Fedro. Traducción de C. García Gual (Gredos, Madrid 2007), 346. Cf. Platon, Werke. Traducido por F. Schleiermacher, vol. I (G. Reimer, Berlin 1855), 80.

11 Cf. E. Des Places, Lexique de la langue philosophique et religieuse de Platon (Les Belles Lettres, Paris 1964), 275 (Platon, Oeuvres complète, t. XIV).

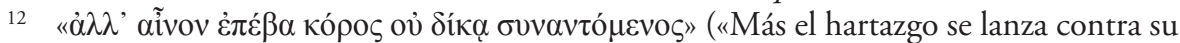
alabanza no acompañándola de justicia...»). Píndaro, Odas Olimpicas II, 95. Traducción de E. Suárez de la Torre (Sociedad Griega de Tipografía, Atenas, 2004), 26-27.

13 Cf. Filón, De agricultura 3. J. Pouilloux, ed. (Cerf, Paris 1961). Sobre este tema, además del artículo citado de M. Harl, puede verse, G. Bostock, "The Sources of 
En relación al mito del Fedro, Filón atribuye el descenso de las almas a la imposibilidad de soportar el kó@os de los bienes divinos ${ }^{14}$. Es decir, reemplaza la idea de impotencia de las almas que aparece en el texto de Platón, por el de una falta de las almas que recibe de la tradición platónica. Y esta falta se produce, como lo señala el mito, en un festín con abundancia de alimentos lo cual se asocia fácilmente al tema de la saciedad o kó@os. Pero el motivo concreto por el cual se produce esta caída admite tres posibilidades. Podría ser que las almas cayeron debido a que no pudieron soportar la borrachera que les produjo el festín de los dioses, tratándose en este caso de una falta de ưß@ıs, o bien cayeron como consecuencia del embotamiento producido por el hartazgo de los bienes divinos o, en tercer lugar, debido a que son incapaces de soportar la plenitud sin embriagarse y entonces no podrían tampoco saciarse de los bienes de los dioses sin emborracharse y caer ${ }^{15}$.

Sea cual fuere el caso, es posible comprobar que antes de Orígenes el término kógos era de uso en el ámbito escolar y filosófico poseyendo siempre el significado de exceso y saciedad y aplicado, en muchos casos, al motivo de la caída de la almas.

\section{LA CAÍDA EN ORÍGENES}

Afirma Orígenes en el capítulo 44 del Contra Celsum que el bien se comunica a las criaturas a través de la alimentación con el pan vivo y la bebida verdadera; pero si a alguna de ellas le falta ese alimento por su propia negligencia, pierden sus alas y caen ${ }^{16}$. Los seres generados necesitan, para conservar su vida, alimentarse, lo cual es su responsabilidad. Es decir que, si dejan de hacerlo, son ellos responsables de la consecuencia que esto acarrea: la caída, o bien, la imposibilidad de elevarse con sus alas a la contemplación por la sencilla razón de que las han perdido. Esta irresponsabilidad toma el nombre, en este caso, de negligencia o descuido. Orígenes utiliza el término @ِ $\alpha \theta v \mu \eta ́ \sigma \alpha v \tau$ os que posee la idea de

Origen's Doctrine of Pre-Existence» en L. Lies, ed., Origeniana Quarta: Die Referate Des 4. Internationalen Origenskongresses (Innsbruck-Vienna 1987), y algunos títulos más en D. T. Runia, Philo of Alexandria. An Annotated Bibliography 19871996 (Vigileae Christianae; Brill, Leiden 2001).

14 Cf. FILón, Quis rerum divinarum heres sit 240. M. Harl, ed. (Cerf, Paris 1966).

15 Cf. M. Harl, «Recherches sur l〉origénisme...», 380.

16 Orígenes, Contra Celse VI, 44. M. Borret, ed., vol. III (Sources Chrétiennes 147. Cerf, Paris 1969), 286. 
indiferencia, aletargamiento o dejadez. La misma idea aparece en el capítulo siguiente pero, en este caso, utiliza un vocabulario diverso. Afirma que algunas criaturas espirituales cayeron debido a su "negligencia con

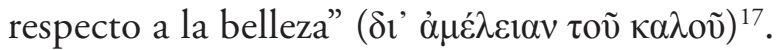

Como observa Harl, la metáfora de la alimentación de las almas a través de la contemplación que utiliza Orígenes, deja lugar en otras de sus obras a expresiones más abstractas, en las que "alimentarse" es "volverse" hacia Dios, y no alimentarse es "desviarse" de Dios ${ }^{18}$. Sin embargo, el vocablo que utiliza con más frecuencia es el de tensión del alma hacia Dios siendo, de este modo, el motivo de la caída un relajamiento o un cesar en esa tensión. En el Comentario al Evangelio de Juan, por ejemplo, afirma que si el Hijo forma parte de la divinidad, es porque "persiste sin ninguna interrupción en la contemplación de la profundidad paternal”, es decir, está en continua tensión hacia el Padre ${ }^{19}$. Y en el Comentario al Evangelio de Mateo, explica que si las almas se clasifican en diferentes "razas" esto es debido al modo en que tienden o relajan su voluntad con respecto a $\operatorname{Dios}^{20}$. Si caen o descienden, es como consecuencia de un descuido o de una ignorancia con respecto a lo bello ${ }^{21}$. En última instancia, se trata del mismo concepto de fondo: la negligencia del nous que se concretiza en el abandono de su nutrición que se realiza en la contemplación, o en el relajamiento de su tensión con respecto a Dios o con respecto a lo bello.

En De principiis, Orígenes trata de un modo más directo la caída de las almas. En II, 9 propone un relato de este acontecimiento cuando trata acerca de la creación del mundo material. Allí dice: “...sed desidia et laboris taedium in servando bono et aversio ac neglegentia meliorum initium dedit recedendi a bono"22. Estos serían los motivos posibles de la falta que originó la tragedia de las almas: la desidia, el relajamiento en el trabajo de conservar el bien, el rechazo y la negligencia del bien. El

Orígenes, Contra Celse VI, 45; p. 290.

1 Cf. M. HaRL, «Recherches sur l>origénisme...», 389.

19 Orígenes, Commentaire sur saint Jean II, 2,18. C. Blanc, ed. (Sources Chrétiennes 120-bis; Cerf, Paris 1966).

20 Orígenes, Commentaire sur l'Évangile selon Matthieu XI, 17. R. Girod, ed. (Sources Chrétiennes 162; Cerf, Paris 1970).

21 Orígenes, Contra Celse VII, 69.

22 Orígenes, Traités des principes II, 9, 2. H. Crouzel y M. Simonetti, edd. (Sources Chrétiennes 252, Cerf, Paris 2008), 354, 43-45. 
rechazo, o aversio, en realidad no es un motivo sino más bien la descripción de un hecho. De los tres restantes, la negligentia meliorum podría

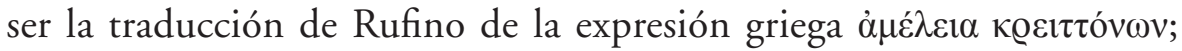
desidia y labores taedium designan ideas semejantes: el abandono del esfuerzo debido a la pereza o laxitud, o bien, el relajamiento de una tensión previa. La expresión labores taedium podría expresar el concepto

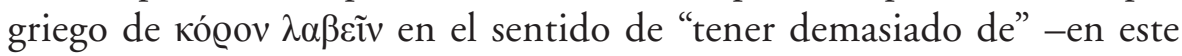
caso-, conservar el bien ${ }^{23}$.

En el libro I, 3,8 del mismo tratado, Orígenes vuelve a referirse al tema. Lo que allí quiere demostrar es que la acción continua de Dios debe corresponderse a la recepción continua, por parte del hombre, de esta acción. Escribe: “...ita perdurare debemos (sanctam et beatam vitam), ut nulla umquam nos boni illius satietas capiat,... Si autem aliquando satietas cepit aliquem..., sed revocare pedem et redire ad statum suum..." ${ }^{24}$. “...debemos perdurar (en la vida santa y bienaventurada) sin que nunca nos atrape la saciedad del bien... Y si algún día la saciedad atrapa a alguno... este podrá reformar su camino y volver a su estado...”. En este caso, los dos conceptos -saciedad y negligencia-, aparecen asociados a la misma idea que quiere transmitir Orígenes. Se trata de un relajamiento en el bien, siendo el alma responsable del mismo. Aparece un abandono progresivo de la tensión, que se manifiesta ya no como un disgusto por el bien, sino como un abandono progresivo de la tensión al bien. Es por eso que se trata de una suerte de fatiga o negligencia. Y así, el motivo de la culpa es el abandono de la tensión, la detención en el movimiento o la distensión en la vigilancia ${ }^{25}$.

\section{LA CAÍDA EN EVAGRIO PÓNTICO}

Las referencias más importantes de Evagrio al motivo que ocasiona la caída del nous aparecen en las Kephalaia gnostica, texto que posee características especiales. Debido a las condenas origenistas del siglo VI,

23 Cf. M. HARL, «Recherches sur l'origénisme..., p. 392.

24 Orígenes, Traités des principes I, 3, 8.

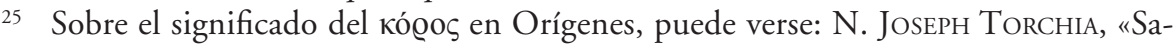
tiety and the Fall of Souls in Origen's De Principiis», en E. A. Livingstone, ed. (Studia Patristica 18,3, the Second Century, Tertullian to Nicea in the West, Clement and Origen, Cappadocian Fathers; Cistercian Pub. - Peeters Press, Kalamazoo, Michigan; Leuven 1989). 
se conservan solo fragmentos del texto griego dispersos en florilegios y en obras de otros autores. El texto completo solamente se encuentra en dos versiones siríacas y una armenia. Según la teoría de Guillaumont, la primera versión siríaca, del siglo $\mathrm{V}$, reproduce el escrito evagriano pero con muchas correcciones destinadas a eliminar o atenuar las posturas más origenistas, y es esta la versión que reproduce el texto armenio. La segunda versión siríaca, compuesta en el siglo VI, en cambio, toma a la anterior pero la corrige a fin de hacerla más fiel al original ${ }^{26}$. Casiday, en cambio, considera que la versión más cercana al original evagriano es la primera $^{27}$.

Evagrio, cuando hace referencia a la deflexión del nous habla de "movimiento" más bien que de "caída". Esta última expresión la utiliza para referirse a las consecuencias del movimiento. Es decir, primero se habría dado un movimiento que originó la caída cósmica ${ }^{28}$. Se trata de una situación que no debe ser ubicada en el tiempo. Como explica Bunge, Evagrio habla de realidades metahistóricas con un lenguaje radicado en el espacio y el tiempo, es decir, con el único lenguaje que poseemos para hablar de esas realidades. Como afirman los Capitulos de los discípulos de Evagrio, el nous preexiste al cuerpo "pero no en el tiempo, porque el tiempo pertenece a la naturaleza corporal" 29 .

La referencia a los motivos de este primer movimiento del nous aparece en dos capítulos diversos de las Kephalaia gnostica. En I, 49 escribe: “...(el nous), por su negligencia, aparta su mirada de ella (la Unidad),

26 La edición de la primera versión siríaca, en adelante S1, fue realizada en 1912 por W. Frankenberg, Evagrius Ponticus (Abhandlungen der Königlichen Gesellschaft der Wissenschaften zu Göttingen. Philologisch-Historische Klasse, Waidmannsche Buchhandlung, Berlin 1912). Una nueva edición con la versión S1 y S2 y traducción al francés es la ya citada en nota 3. Sobre las Kephalaia gnostica también puede verse: A. Guillaumont, Les "Kephalaia Gnostica» d'Évagre le Pontique et l'histoires de l'Origénisme chez les grecs et chez les syriens (Patristica Sorboniensia 5; Cerf, Paris 1962) y Un philosophe au désert. Évagre le Pontique (Vrin, Paris, 2009), 102-105.

27 Cf. A. Casiday, Reconstructing the theology of Evagrius Ponticus. Beyond heresy (Cambridge University Press, Cambridge 2013).

28 Cf. M. Tobon, Apatheia in the Teachings of Evagrius Ponticus (University College, London 2010), 18-19.

29 [Evagrio Póntico], Chapitres des disciples d'Évagre, c. 25. P. Gehin, ed. (Sources Chrétiennes 514; Cerf, Paris 2007). Cf. G. Bunge, Evagrios Pontikos: Briefe aus der Wüste (Beuroner Kunstvlg, Trier 1985), 396: 52. 
y por el hecho de estar privado de ella, engendra la ignorancia"30. Ambas versiones siríacas son idénticas en este caso. El segundo kephalaion donde se menciona la caída es III, 28 y, en este caso, sí hay una diferencia importante entre ambas versiones. La S1, o versión larga, dice: "El alma pecadora es el nous puro que, por su negligencia, cayó de la contemplación de la Unidad santa y tiene necesidad de obtener, por un gran trabajo, la imagen perfecta de la Trinidad santa, de la cual cayó". La S2, o versión breve, en cambio, dice: "El alma es el nous que, por negligencia, cayó de la unidad y que, por su descuido, descendió al rango de la praktiké". En ambos casos el texto siríaco utiliza la misma palabra: papwpoia (mahmānūwāta), es decir, negligencia.

También hay coincidencia en ambos textos en cuanto al proceso que indica Evagrio: el nous se aparta de la Unidad debido a su negligencia. La referencia es a un cambio del estado original del nous, previo a la caída, la cual es provocada por una acción voluntaria, la negligencia. Por eso, Evagrio considera que se trata de un alma pecadora (uf-hi - hatāyāta), con lo cual indica el carácter voluntario de esa caída.

Evagrio, además, utiliza en este kephalaion dos términos distintos según se trate del estado de los seres racionales antes o después de la caída. Ellos son a, i (hawea) nous, y , פai (napshāa) alma. El nous es "el que ve a la Trinidad santa" ${ }^{31}$, y ha sido creado intemporalmente ${ }^{32}$. Es la imagen de Dios en el hombre y el centro de su identidad personal. Persiste a través de los juicios sucesivos, a diferencia de los otros componentes que están formados por los cuatro elementos, tales como el cuerpo, las emociones o las aptitudes ${ }^{33}$. Pero el movimiento rompió la paz en la que se encontraban los noein: "El movimiento primero de los seres racionales es la separación del nous de la Unidad que estaba en él" ${ }^{4}$. Y, una vez producida esa separación o caída, el nous se convirtió en alma ${ }^{35}$. De aquí la definición de alma que introduce Evagrio en el texto de la Kephalaia gnostica que analizamos: el nous caído.

\footnotetext{
30 Evagrio Póntico, Les six centuries des Képhalaia Gnostica d'Évagre le Pontique, 41.

31 KG III,30.

32 Cf. KG VI,9.

33 Cf. L. Dysinger, Psalmody and Prayer in the Writings of Evagrius Ponticus (Oxford University Press, Oxford 2005), 177.

4 KG III,22.

35 Evagrio Póntico, Letter to Melania. M. Parmentier, ed. (Garland, New York, 1995), 43.
} 
Sin embargo, para los objetivos de este trabajo resulta fundamental determinar el significado que Evagrio le otorga al concepto negligencia y que es la causa de la caída de los noein. Mi hipótesis es que se trata de un concepto asimilable al de acedia, tal como lo desarrolla en varias de sus obras. Son tres los puntos de apoyo sobre los cuales el Póntico caracteriza a la acedia en el Tratado práctico. Afirma que la acedia (1) inspira al monje aversión por el lugar en el que se encuentra, (2) provocando que comience a desear otros lugares y (3) poniendo ante sus ojos la fatiga de la ascesis ${ }^{36}$. En primer lugar, vemos que el fenómeno de la acedia se estructura claramente como un dis-gusto del estado presente que se manifiesta como un deseo de cambio. La propia vida que el monje ha elegido y en la que se encuentra, despierta en él un rechazo que no produce, al menos en lo inmediato, una rebelión violenta, sino más bien una desidia o descuido de los deberes inherentes a la vida monástica. Explica Evagrio que el monje pasa sus horas parado junto a la ventana de su celda esperando ver pasar a alguien para distraerse, o buscando pretextos -que en apariencia son muy santos, tales como visitar a un enfermo o hablar con algún hermano que pasa- para alejarse de su lugar. Es decir, en sus inicios al menos, la acedia no provoca el deseo de abandonar la vida monástica, sino más bien el deseo de buscar otros lugares, o dejar de ser lo que se es para ser otra cosa.

La aversión de la celda es también uno de los modos que utiliza Evagrio para definir a la acedia en otro de sus tratados -el De vitiis quae opposita sunt virtutibus-, en el que dedica el capítulo IV a tratar este logismos. En este caso, comienza ofreciendo una serie de definiciones

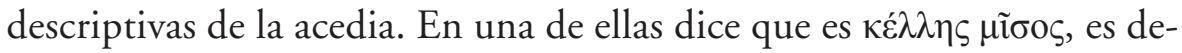
cir, "odio a la celda" ${ }^{37}$. El autor ubica en el corazón mismo de la acedia, o señala que su esencia es un odio, es decir, la reacción de la afectividad frente a un mal presente, siendo este mal su propia celda. Resulta difícil pensar que la referencia sea exclusivamente a un lugar físico -las paredes que constituyen el hábitat del monje- sino que más bien se señala que ese mal presente objeto del odio es un estado de vida que se sintetiza en la celda. La vida de los monjes del desierto egipcio transcurría de modo casi ininterrumpido en su celda.

36 Evagrio Póntico, Traité pratique, 6. A. et C. Guillaumont, ed. (Sources Chrétiennes 171; Cerf,. Paris 1971), 520-527.

37 Evagrio Póntico, De vitiis quae opposita sunt virtutibus, IV. PG 79, 1144C. 
El motivo que aduce Evagrio para que el monje experimente esta situación de aversión a su celda es la fatiga que le provoca la vida ascética que aún deberá soportar y que se le presenta anticipadamente a su vista. El autor utiliza en este caso el término tóvos, que posee una dualidad de significados ${ }^{38}$. Por una parte, hay en él una fuerte referencia al trabajo duro y cansador pero también posee la idea de tedio o de una labor que se hace a disgusto. Así, lo que aparece en la imaginación del monje acedioso es un futuro sin sabores, sin variaciones y aburrido. Es la monotonía cierta de su vida, y que se percibe en su totalidad, la que le provoca la fatiga o el tedio de la permanencia en su elección.

Aparece también aquí una coincidencia que es importante señalar. Cuando Evagrio habla de aversión por el lugar en el que se encuentra el monje, utiliza le expresión griega $\mu$ ĩoo que significa tanto odio como un fuerte disgusto ${ }^{39}$. Se trata de una idea análoga a $\pi$ óvos, en tanto que si bien esta connota el rechazo u odio hacia algo, también está presente la idea de un intenso disgusto. Pareciera, entonces, que la acedia no implica una suerte de rechazo aguerrido o violento, sino más bien una disminución del afecto, o de la actividad, que antes se poseía o se realizaba y que conlleva, sí, una suerte de aversión pero signada por el descuido o carencia de energía. La acedia, entonces, esconde en el fondo la negligencia en la propia actividad y en el bien que se eligió en su momento.

Como vimos, se trata de un bien que está simbolizado en la celda que, para Evagrio y para los Padres del desierto egipcio, es mucho más que un lugar. Es la expresión de la unidad del alma con Dios y de la perseverancia en la elección primera y fundante de la propia vida del monje. Abandonar la celda, o ser negligente y descuidado en su observancia, es decir, ser acedioso, conduce, en última instancia, al abandono de la propia vida y a la transformación progresiva en lo que no se era y en lo que no se debía ser. En otras palabras, conduce a la perdición. De aquí entonces que el logismos de la acedia sea señalado por Evagrio con mucha insistencia como uno de los más peligrosos.

Finalmente, es relevante también señalar una imagen que aparece en la primera parte del capítulo que Evagrio dedica a la acedia en el Tratado práctico y en torno a la cual se estructura su desarrollo: el sol. Allí

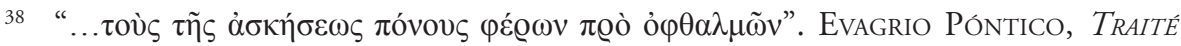
PRATIQUE 12, 526, 20-21.

39 Evagrio Póntico, Traité pratique, 6, 522, 9.
} 
se dice que al monje atacado por la acedia le parece que el sol se mueve muy lentamente, o está inmóvil, y que el día tiene cincuenta horas. Y, enseguida, agrega que mira continuamente a través de la ventana de su celda, observando el sol a fin de descubrir cuánto falta para que llegue la hora novena ${ }^{40}$.

Esta descripción del estado interior del monje atacado por la acedia que realiza Evagrio puede ser sintetizada con un solo término: tedio. De hecho, es el concepto al que recurren otros Padres y autores medievales para caracterizar a la acedia. Pero ¿qué es el tedio? En primer lugar, es una falta de gusto, o disgusto, hacia la propia vida, o mejor, hacia aquello que es debido. La persona asaltada por el tedio ya no experimenta placer por hacer lo que debe hacer, o por cumplir con su deber que es, para ella, el bien. En este sentido, el tedio es el relajamiento en la búsqueda del bien, que es el modo en el que muchos medievales caracterizarán a la acedia. Situada la persona en tensión hacia un bien arduo que debe alcanzar, y habiendo mantenido durante un tiempo esa tensión, se relaja porque ya no encuentra gusto en ella. El tedio es la manifestación de un quiebre en la decisión del monje que deja de empeñarse en la búsqueda del fin, aunque esa decisión no implique necesariamente una suerte de rebeldía o de violencia. Más bien, se trata de un negligente "dejar de hacer” o un relajamiento en relación al propio deber. O, también, un cansancio de tender al bien. Deja de desear lo que deseaba y comienza a buscar otros objetos de deseo. Utilizando una imagen preciada por los Padres, se enfría en el amor.

La caracterización que Evagrio Póntico realiza de la acedia puede, entonces, ser asimilada a la idea de negligencia y, de ese modo puede sostenerse que, en el pensamiento de este autor, es la acedia la causa de la caída de los noein o, en otras palabras, de la tragedia cósmica.

El nous, antes de su caída, ha comenzado también, como el monje, a "buscar otros lugares". La perfecta monotonía de su "estar" en la Unidad se le presenta como tediosa y, por ese motivo, relaja su tensión hacia el bien. Se ha hartado de permanecer en la invariabilidad de su vida de

40 Cf. Evagrio Póntico, Traité pratique 12, p. 520-522. La hora novena era el momento en el que habitualmente se tomaba la única comida del día. Ver: Apopththegmata Patrum, Antonio 34; Macario 33, etc. Ver también L. Regnault, La vie quotidienne des Pères du Désert en Égypte au IV siècle (Hachette, Paris 1990), 77-79. 


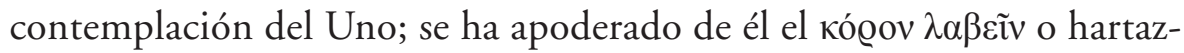
go de la propia vida.

Pero la rebelión del nous no es una rebelión violenta contra el Uno, sino una desidia o negligencia, provocada por el hartazgo con respecto a su deber o, más bien, a su vida misma que consiste en permanecer en la Unidad originaria. Y así, el nous deja de ser quien es; su existencia se transforma puesto que deja de ser quien es -nous-, para transformarse en otro - psique-, ya que se enfrió en el amor ${ }^{41}$.

41 "Sicut ergo Deus ignis est, et angeli flamma ignis, et sancti quique spiritu ferventes: ita e contrario hi, qui deciderunt a dilectione Dei, sine dubio refrixisse in caritate eius ac frigidi effecti esse dicendi sunt”. OríGEnES, DE PRINCIPIIS II, 8, 3; 156, 22-25. 
